\title{
O material manipulável no ensino e aprendizagem das noções básicas de geometria analítica a um aluno com cegueira
}

\author{
Lucélia Valda de Matos Cardoso \\ Elielson Ribeiro Sales²
}

\begin{abstract}
RESUMO
Este artigo é um recorte da pesquisa de mestrado na qual teve como objetivo desenvolver um material manipulativo como recurso para o processo de ensino e aprendizagem das Noções básicas de Geometria Analítica a um aluno com cegueira adquirida. A pesquisa foi desenvolvida em uma escola pública estabelecida em Mosqueiro (distrito de Belém/PA) no bairro de Carananduba, envolvendo somente um aluno do terceiro ano do Ensino Médio. A pesquisa de abordagem qualitativa utilizou como metodologia o estudo de caso, a fim de entendermos quais as contribuições deste recurso ao ensino e aprendizagem do discente. Os resultados obtidos demonstraram que o uso do material manipulável possibilitou aprendizado significativo do aluno, por meio da compreensão dos conceitos matemáticos das noções básicas de Geometria Analítica.
\end{abstract}

Palavras-chave: Geometria Analítica. Materiais Manipulativos. Ensino e Aprendizagem de Cego.

\section{Manipulable material in teaching and learning analytical geometry basics for}

\section{a blind student}

\begin{abstract}
This article is an excerpt from the master's research which aimed to develop a manipulable material as a resource for the process of teaching and learning the Basics of Analytical Geometry to a student with acquired blindness. The research was conducted in a public school settled in Mosqueiro (Belém district / PA) in the Carananduba neighborhood, involving only a third year high school student. The

1 Graduada em Matemática pela Universidade do Estado do Pará (UEPA). Especialista em Educação Matemática pela Universidade Federal do Pará (UFPA) e em Educação Especial pela Faculdade Montenegro. Mestre em Educação Matemática (UFPA). Orcid iD: https://orcid.org/0000-0002-3482-2489. E-mail: Iuceliamatosmat@gmail.com

2 Professor Adjunto II da Universidade Federal do Pará no Curso de Licenciatura Integrada em Ciências, Matemática e Linguagens, professor do Programa de Pós-Graduação em Educação em Ciências e Matemáticas (PPGECM), vice-coordenador do Programa de Doutorado em Educação em Ciências e Matemática (PPGECEM), oferecido pela Rede Amazônia (REAMEC) polo UFPA, coordenador do Grupo Ruaké (Grupo de Pesquisa em Educação em Ciências, Matemáticas e Inclusão), membro fundador do GT13 - Diferença, Inclusão e Educação Matemática da Sociedade Brasileira de Educação Matemática e Consultor ad hoc da CAPES. Orcid iD: https://orcid.org/0000-0001-6242-582X. E-mail: esales@ufpa.br
\end{abstract}


qualitative research used as methodology the case study in order to understand the contributions of this resource to the teaching and the student's learning. The results showed that the use of manipulable material made it possible for the student to learn significantly by understanding the mathematical concepts of the basics of Analytical Geometry.

Keywords: Analytical Geometry. Manipulative Materials. Blind Teaching and Learning.

\section{La manipulación de material en la enseñanza y el aprendizaje de las nociones básicas de geometría analítica para un estudiante ciego}

\section{RESUMEN}

Este artículo es un extracto de la investigación de Maestría que tenía como objetivo desarrollar un material manipulable como recurso para el proceso de enseñanza y aprendizaje de los Fundamentos de la Geometría analítica para un estudiante con ceguera adquirida. La investigación se realizó en una escuela pública de Mosqueiro (distrito de Belém / PA) en el vecindario de Carananduba, involucrando solo a un estudiante de secundaria de tercer año. La investigación cualitativa utilizó como metodología el estudio de caso, con el fin de comprender las contribuciones de este recurso a la enseñanza y el aprendizaje del alumno. Los resultados mostraron que el uso de material manipulable hizo posible que el estudiante aprendiera significativamente al comprender los conceptos matemáticos de los conceptos básicos de la Geometría Analítica.

Palabras clave: Geometría analítica. Materiales manipuladores. Enseñanza y aprendizaje a ciegas.

\section{A inclusão no Brasil aspectos históricos e legais}

Para Hildebrandt (2004), a primeira instituição que agregou alunos cegos foi fundada em 12 de setembro de 1854, por meio do Decreto Imperial n. 1.428, D. Pedro II, no Rio de Janeiro, o Imperial Instituto dos Meninos Cegos. A fundação do Imperial Instituto deu-se, em grande parte, a José Álvares de Azevedo; um cego brasileiro, que estudou no Instituto dos Jovens Cegos de Paris.

Em 1890, no governo republicano, segundo Hildebrandt (2004) o marechal Deodoro da Fonseca; chefe do governo provisório e Benjamin Constant Botelho de Magalhães; ministro da instrução Pública, Correios e Telégrafos, assinaram o decreto n. 408, mudando o nome do instituto para 
Instituto Nacional dos Cegos e aprovando seu regulamento. Em 24 de janeiro de 1891, pelo Decreto n. 1.320, o instituto passou a chamar-se Instituto Benjamin Constant (IBC), até os dias atuais, em homenagem ao ex-professor de Matemática e ex-diretor, Benjamin Constant Botelho de Magalhães. Desse modo, consideramos que a história da escolarização dos deficientes visuais no Brasil deu-se a partir do Instituto Benjamin Constant, no qual era ministrado desde a Aritmética no ensino primário até noções de Trigonometria no secundário.

Partindo do fato de que no IBC, ensinava-se Matemática, o que nos faz aventar que a deficiência visual não impede ao estudante aprender Matemática, corroborando com Fernandes (2004) ao afirmar:

\footnotetext{
Recebendo os estímulos adequados para empregar outros sentidos: como tato, a fala e a audição; o educando sem acuidade visual estará apto a aprender como qualquer vidente, desde que se respeite à singularidade do seu desenvolvimento cognitivo, portanto as principais dificuldades não são necessariamente cognitivas, mas sim de ordem material e técnica, e que frequentemente, condicionam o ritmo de trabalho de um aluno cego na hora de aprender matemática (FERNANDES, 2004, p. 218-219).
}

Em consonância com o pensamento de Fernandes (2004) a pessoa cega necessita de procedimentos pedagógicos específicos, pois exige requisitos diferenciados para o ensino. Essa reflexão é aquela que indica que o ensino se dá por vias alternativas, já que a informação não pode ser obtida por meio da visão.

Para favorecer a efetiva participação e integração do cego é importante, a seleção, a adaptação e uso de recursos materiais que transmitam a informação que não pode ser obtida através dos olhos. Desse modo, nos debruçamos sobre como desenvolver um material manipulativo como recurso para o processo de ensino e aprendizagem das Noções básicas de Geometria Analítica a um aluno com cegueira adquirida.

Antes de abordar a questão norteadora, veremos a seguir os aspectos legais que asseguram o direito do aluno com deficiência ao ensino e aprendizagem. 


\title{
Aspectos legais
}

O acesso dos estudantes da Educação Especial às escolas de ensino regular, no Brasil, é garantido por lei. Direito este assegurado desde a LDBN, Lei n.024/61 e pela Constituição da República Federativa do Brasil de 1988. Em ambas, se prevê a oferta de matrículas para alunos com deficiência e, preferencialmente, na rede regular de ensino. Da Constituição Federal de 1988, respectivamente, ambos os artigos tratam da igualdade de condições de acesso e permanência na escola, com oferta de atendimento educacional especializado na rede regular de ensino, preferencialmente. Nesse sentido, alguns autores sustentam:

\begin{abstract}
Vale sempre enfatizar que a inclusão de indivíduos com necessidades educacionais especiais na rede regular de ensino não consiste apenas na sua permanência junto aos demais alunos, nem na negação dos serviços àqueles que dele necessitem. Ao contrário, implica uma reorganização do sistema educacional, o que acarreta a revisão de antigas concepções e paradigmas educacionais na busca de se possibilitar o desenvolvimento cognitivo, cultural e social desses alunos, respeitando suas diferenças e atendendo às suas necessidades (GLAT; NOGUEIRA, 2002, p.26).
\end{abstract}

As orientações para uma educação inclusiva estão bem documentadas e legisladas. Há o apoio legal da Constituição da República Federativa do Brasil/1988, especialmente no inciso III do Art $^{\circ}$. 208, da Lei ${ }^{\circ}$ 12.010, de 2009, que determina o direito das crianças com deficiência à educação. De acordo com as orientações e leis, a educação inclusiva está, aparentemente, com todos os recursos e apoio pedagógico aos alunos. Mas, apesar de todo o aparato legal, esse processo ainda caminha de forma bem "tímida".

Capellini e Rodrigues (2009) afirmam que os direitos estão explícitos na lei, mas nem sempre efetivado por algumas instituições. No entanto, segundo as autoras, apesar da falta de condições reais para o cumprimento das leis. "É importante lembrar que, ao longo dos séculos, muitas conquistas foram alcançadas" (p.358), como exemplo, a LDB n 9.394/96, a Resolução CNE/CEB no 2/01, a Política de Educação Especial na Perspectiva da 
Educação Inclusiva. Logo, "não podemos acreditar que estamos partindo do zero, como se tudo ainda estivesse por fazer" (p.358).

Deste modo, o sistema brasileiro fez a adequação na sua legislação visando atender à Constituição, por meio da Lei de Diretrizes e Bases da Educação Nacional (LDBEN n 9.394/96), no capítulo $\vee$, do artigo 58, ficou estabelecido a Educação Especial como modalidade de educação escolar oferecida, preferencialmente, na rede regular de ensino (BRASIL, 1996).

A Resolução CNE/CEB n 2, de 11 de fevereiro de 2001, no seu artigo $2^{\circ}$, determinou que os sistemas de ensino devessem matricular todos os alunos, cabendo às escolas organizarem-se para o atendimento aos estudantes com necessidades educacionais especiais, assegurando que tenham as condições necessárias para uma educação de qualidade.

Sendo assim, a Política de Educação Especial na Perspectiva da Educação Inclusiva (MEC, 2008) tem como objetivo o acesso, a participação e a aprendizagem dos alunos com deficiência, [...], orientando os sistemas de ensino para promover respostas às necessidades educacionais especiais.

\section{Deficiência Visual}

No Brasil, os dados do Censo Demográfico 2010 do Instituto Brasileiro de Geografia e Estatística - IBGE revelaram que 23,9\% dos residentes no país, possuíam um dos tipos de deficiência: visual, auditiva, motora e mental ou intelectual. Destas, o maior número de ocorrências é a deficiência visual, correspondendo a 18,6\% da população brasileira, sendo que dos 45.606. 048 $(23,9 \%), 1,6 \%$ desse geral, são totalmente cegos, equivalente a 729.696 brasileiros cegos. E dos 729.696 cegos de todo o território nacional $6,26 \%$ se encontrava na região Norte.

De acordo com a Política Nacional de Educação Especial considerase pessoa com deficiência:

Àqueles que têm impedimentos de longo prazo, de natureza física, mental, intelectual ou sensorial, que em interação com diversas barreiras podem ter restringida sua participação plena e efetiva na escola e na sociedade (MEC/PNEE, 2008, p. 15). 
Em relação ao deficiente sensorial em especial em relação a visão pode-se classificar em baixa visão, segundo o Ministério da Educação (MEC, p.34) pessoas com baixa visão são aquelas que apresentam "desde condições de indicar projeção de luz até o grau em que a redução da acuidade visual interfere ou limita seu desempenho". E o cego, sendo que este último por ser objeto deste estudo será apresentado a seguir:

\section{Cegueira}

Segundo o Ministério da Educação (MEC, p. 33) "a cegueira é a perda total da visão até a ausência de projeção de luz". E manifestada durante os primeiros anos de vida é considerada cegueira congênita, enquanto a perda da visão de forma imprevista ou repentina é conhecida como cegueira adquirida.

Deste modo, o processo de aprendizagem se fará por meio dos sentidos remanescentes (tato, audição, olfato e paladar), utilizando o Sistema Braille, como principal meio de comunicação escrita. Dessa forma, para proporcionar autonomia e independência para participar de jogos e atividades lúdicas é necessário que o ambiente ofereça acessibilidade adequada para o cego. Por isso, se faz necessário promover atividades que estimulem o interesse e a curiosidade do mesmo, para que possa conhecer e identificar fontes sonoras, mover e localizar o corpo no espaço, usar o tato para identificar forma, tamanho, textura, peso, dentre outras propriedades dos objetos.

E as ideias expostas por Vygotsky (1997), complementam ao narrar que a cegueira deve ser compreendida como uma fonte reveladora de atitudes, uma força motriz para a superação de obstáculos e dificuldades, mais do que uma deficiência, defeito ou insuficiência de um órgão ou função. Portanto, precisamos compreender que a pessoa com cegueira e a que é vidente, ambas têm potencialidades para conhecer, aprender e participar ativamente da sociedade. 
Desse modo, é essencial construir um espaço que vise estimular a convivência e a interação com vários meios de acesso à leitura, à escrita e aos conteúdos curriculares.

Nesse processo, vale destacar que a deficiência visual não afeta o aspecto cognitivo do indivíduo. Mas, se deve considerar as características individuais, o tipo de perda, suas reações emocionais, as experiências visuais e a aceitação do indivíduo frente a deficiência visual. Por isso, não se deve utilizar os mesmos recursos para todos os alunos com baixa visão, pois, a prática desenvolvida com um aluno pode não render os mesmos resultados com outro. Desse modo, a deficiência visual pode ocorrer em qualquer idade. Alguns podem nascer sem visão e outros podem adquirir ao longo da vida, em decorrência de um acidente ou doença. Portanto, a deficiência visual não pode ser concebida como a causa de alterações cognitivas, motoras e psicológicas.

A formação dos processos psicológicos superiores como a memória, atenção, a imaginação, o pensamento e a linguagem, são sistemas funcionais dinâmicos que colaboram para a organização da vida, em vários aspectos, e só poderão ser desenvolvidos pelo sujeito por meio da apropriação da cultura. Por isso, a importância da escolarização e da mediação do educador.

\section{Materiais manipuláveis para o ensino e aprendizagem de Matemática}

O uso de materiais manipuláveis segundo Silva (2015) como instrumento para o ensino e aprendizagem de alunos cegos vem mostrando aos professores pesquisadores da área de educação matemática inclusiva, aspectos positivos para a aprendizagem destes alunos.

Fernandes e Healy (2007), após o estudo sobre estímulos háptico, ambas, afirmaram que as ferramentas materiais promovem a compreensão e solução de exercícios matemáticos. 
envolvem conceitos matemáticos usualmente desenvolvidos nas escolas regulares (FERNANDES; HEALY, 2007, p.16).

A partir do exposto acima, verificamos a importância dos materiais manipuláveis na fala de Fernandes e Healy (2007), por mais que sejam simples não podem deixar de envolver os conceitos matemáticos previstos na atividade.

Nesse sentido, entre $O$ conhecimento matemático e sua aprendizagem, existe um processo a ser vivenciado, que pode ser iniciado com o uso de materiais manipuláveis. Pois esses materiais permitem ao aluno criar seus primeiros conhecimentos matemáticos sobre um determinado assunto utilizando o tato.

Vieira e Silva (2007) por meio dos recursos táteis em alto relevo e do código Braille, abordou as formas de flexibilização do conteúdo de geometria, afirmando que a limitação dos alunos cegos poderá ser suprida ao explorar outros sentidos. Para o autor, o concreto é um dos meios que possibilitam aos cegos ter conhecimento das coisas que os rodeiam.

A perda da visão não os limita sentir e presenciar as formas geométricas que os cercam, pois, a partir do toque esses alunos podem "visualizar" toda beleza do mundo geométrico em sua volta. O que parecia então vazio e sem forma, com um simples toque ganha forma e vida na mente desses alunos possibilitando-os, assim, acompanhar o conteúdo (VIEIRA; SILVA, 2007, p. 4).

Assim sendo, tornar acessível o conhecimento matemático ao discente cego que cursa no ensino regular tem se constituído em uma busca constante, tanto pelos professores quanto pelos próprios alunos, uma vez que o estudante cego tem as mesmas condições de aprender Matemática de um aluno vidente. No entanto, é necessário adaptar os recursos didáticos ${ }^{3}$.

Para Cerqueira e Ferreira (2000, p. 24) os recursos didáticos usados na educação de deficientes visuais podem ser obtidos de três formas: "Seleção: utilização dos mesmos materiais que são usados para o ensino de alunos

\footnotetext{
3 Recursos didáticos são: "†odos os recursos físicos, utilizados com maior ou menor frequência em todas as disciplinas, áreas de estudo ou atividades, [...], visando auxiliar o educando a realizar sua aprendizagem de modo mais eficiente, constituindo-se num meio para facilitar, incentivar ou possibilitar o processo ensino aprendizagem" (CERQUEIRA \& FERREIRA, 2000, p.24).
} 
com visão normal, como os blocos lógicos, material dourado, Cuisinaire e outros; Adaptação: alteração de alguns materiais que já existem no mercado, como por exemplo: o baralho de cartas, o metro, a balança, os mapas de encaixe, os jogos e outros; Confecção: construção de materiais com o uso de tacinhas, chapinhas, barbantes, cola quente, botões e outros".

De acordo com a definição de recursos didáticos e, principalmente, pela terceira forma de uso (Confecção) do mesmo, salientamos que este tipo de recurso se classifica como material manipulável que segundo Reys (1971) funciona como base para a compreensão dos conteúdos matemáticos.

Fernandes (2004) ressalta que:

\begin{abstract}
Recebendo os estímulos adequados para empregar outros sentidos: como tato, a fala e a audição; o educando sem acuidade visual estará apto a aprender como qualquer vidente, desde que se respeite à singularidade do seu desenvolvimento cognitivo, portanto as principais dificuldades não são necessariamente cognitivas, mas sim de ordem material e técnica, e que frequentemente, condicionam o ritmo de trabalho de um aluno cego na hora de aprender matemática (FERNANDES, 2004, p. 218 - 219).
\end{abstract}

Além disso, o ensino deve ser planejado e organizado tendo como referência $O$ conhecimento das necessidades individuais e das características dos alunos, ou seja, é preciso reconhecer as diferenças dos alunos, para poder questioná-las e valorizá-las.

Pois, a discriminação tátil é uma habilidade que deve ser desenvolvida com pessoas cegas, além disso, o tato fornece informações sobre tamanho, forma, peso, consistência, espessura, textura, dentre outras.

Para Vygotsky (1998), "o aprendizado das crianças começa muito antes delas frequentarem a escola. Qualquer situação de aprendizado com a qual a criança se defronta na escola tem sempre uma história prévia" (p. 94). Uma vez que, cada aluno cria sua própria relação entre as coisas.

Assim sendo, os estímulos palpáveis contribuem para o desenvolvimento do aprendizado do aluno com deficiência visual, nessa perspectiva, se faz necessário o uso de recursos adaptados para o ensino de vários conteúdos de Matemática. 
Segundo Lírio (2006), nas aulas de geometria, as atividades envolvem conceitos de visualização, o que dificulta ainda mais o aprendizado do conteúdo aos estudantes cegos.

Em consonância com o pensamento de Lírio (2006), os materiais manipuláveis podem representar algumas noções no contexto matemático, tornando os conteúdos acessíveis ao aluno com cegueira. Valendo lembrar, que o uso só dos materiais manipuláveis não irá garantir a aprendizagem do discente com cegueira, pois, estes materiais servem apenas de meios intermediários para o aluno cego, possibilitando a este desenvolver seu pensamento matemático.

Pensando nos trabalhos já realizados com alunos cegos, que elaboramos uma ferramenta tátil, com o objetivo de ensinar as noções básicas de Geometria Analítica.

\section{Metodologia}

A opção metodológica por uso nesta pesquisa foi o estudo de caso em virtude dele representar os propósitos e concepções metodológicas adequadas ao tipo de estudo que realizamos.

Yin (2005) concebe o estudo de caso como estratégia que é geralmente usada quando as questões de interesse do estudo referem-se ao como e ao porquê, e quando o foco se encontra inserido em um contexto da vida real.

Desse modo, reafirmamos a escolha pelo estudo de caso como método de pesquisa na investigação em desenvolver um material manipulativo como recurso para o processo de ensino e aprendizagem das Noções básicas de Geometria Analítica a um aluno com cegueira adquirida. Assim, focalizamos fenômenos sociais como, o processo de inclusão, as estratégias de ensino utilizadas por professores e o uso de materiais manipuláveis na aprendizagem.

Em consonância com o pensamento Edmund Husserl (1986), o fenômeno é tudo aquilo que se mostra, que se manifesta, que surge para a 
consciência e, isto Ihe atribui o significado. Diante disso, entendemos que "o estudo de caso é uma investigação empírica que investiga um fenômeno contemporâneo dentro de seu contexto da vida real" (YIN, 2005, p. 32).

Para tal percurso da pesquisa sustentamos o uso do estudo de caso, devido à obtenção de dados mediante contato direto e interativo do pesquisador com a situação, com investigação intensiva com os participantes e emprego de diversos métodos de coleta de dados para entendimento e interpretação dos fenômenos presentes na pesquisa.

Desse modo, procuramos a compreensão e explicação de diversos aspectos, quanto à produção de informações acerca da pesquisa, para desvendar a realidade e reconstruir as manifestações dos fenômenos (vivências do mundo percebido pelo aluno) observados. Segundo Yin (2005), a observação participante é uma modalidade de observação na qual o pesquisador assume um papel ativo na pesquisa, realizando a produção de dados para adquirir informações sobre determinados aspectos da realidade.

A observação participante é uma modalidade especial de observação na qual você não é apenas um observador passivo. Em vez disso, você pode assumir uma variedade de funções dentro de um estudo de caso e pode, de fato, participar dos eventos que estão sendo estudados (YIN, 2005, p. 116).

A pesquisa foi realizada na escola estadual de ensino fundamental e médio da rede pública de ensino ${ }^{4}$, estabelecida em Mosqueiro (distrito de Belém/PA) no bairro de Carananduba. A escolha por essa escola deu-se após um diálogo com um professor de Matemática da instituição, pois este buscava meios de auxiliar na aprendizagem do aluno cego, assim, a escola nos serviu como fonte de dados.

Em relação ao espaço físico, a escola tem apenas algumas rampas como requisito de acessibilidade, quanto aos demais requisitos a escola não possui, por exemplo, piso tátil, inscrições em Braille ou ampliada, entre outras adequações necessárias à inclusão. Apesar de a instituição ter sido

\footnotetext{
${ }^{4}$ Esta escola a partir deste tópico será chamada de escola regular, para preservar sua identidade.
} 
reformada em 2011, as adaptações para receber o público (com e sem deficiência) não foram realizadas.

Para a análise de dados utilizamos as atividades relativas aos assuntos vistos em sala de aula regular, levamos em consideração a revisão bibliográfica, a observação e o diálogo, assim como a escrita em Braille realizada pelo aluno. E, como registros, foram utilizados o caderno de campo, documentos, entrevistas, fotografias e as gravações em vídeo.

Para Yin (2005) o estudo de caso não precisa ficar limitado a uma única fonte de evidências. Na verdade, a maioria dos melhores estudos baseia-se em uma ampla variedade de fontes.

As atividades foram desenvolvidas nos "encontros" em ordem cronológica (El a E8). Deste modo, os oitos momentos referentes ao desenvolvimento das atividades foram descritos sequencialmente junto das figuras referentes a cada encontro.

Alves ${ }^{5}$ tinha 33 anos e estava cursando a $3^{a}$ série do ensino médio. 0 meu primeiro contato com ele se deu no ano de 2015 ao visitar a escola regular.

No primeiro encontro, percebemos o quanto era reservado e, apesar de ser maior de idade sua mãe o acompanhava em todas as atividades, mesmo tendo adquirido a cegueira há um tempo, Alves não gostava de usar a bengala, por isso, precisava do apoio de sua mãe para se locomove.

Diante dessa situação e também por respeito à família de Alves solicitamos a autorização de sua mãe. Segundo a genitora de Alves, ele adquiriu a cegueira aos 11 anos de idade, por meio do glaucomab.

\section{Encontro (E1 a E2)}

As atividades com Alves foram trabalhadas em tempos de 90 minutos, cada encontro. A atividade tratava sobre os "Números Inteiros na reta

\footnotetext{
${ }^{5}$ Nome fictício a fim de preservar a identidade do participante da pesquisa.

6 Glaucoma é uma neuropatia óptica progressiva (doença do nervo óptico) caracterizada por alterações típicas do nervo e da camada de fibras nervosas da retina que o formam. Em sua fase inicial o glaucoma é assintomático. Algum tempo depois de instalada a doença, que a pessoa começa a experimentar uma redução do campo visual, que pode levar à perda completa da visão.
} 
numérica". Em uma reta numerada cada ponto corresponde a um número e cada número corresponde a um ponto, dessa maneira, temos um sistema de coordenadas na reta. O conjunto dos números inteiros é representado pelo símbolo $\mathbb{Z}$, pertencem a esse conjunto os números inteiros positivos e inteiros negativos e o zero (origem). Nessa etapa, assim como na anterior, o aluno descreve o que seu conhecimento prévio the permitiu perceber, para que pudéssemos identificar tais conhecimentos para relacionarmos, em seguida, como os materiais manipuláveis auxiliariam no seu aprendizado.

Figura 1 - Coordenadas sobre uma reta numérica

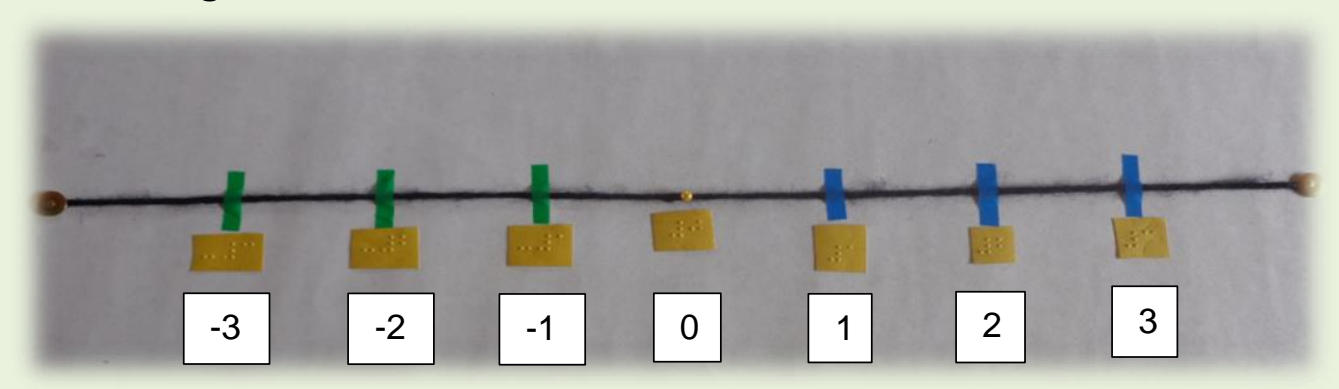

Fonte: Autor.

Segundo Ausubel (1982) a aprendizagem é muito mais significativa à medida que o novo conteúdo é incorporado às estruturas de conhecimento de um aluno e adquire significado para ele a partir da relação com seu conhecimento prévio. Assim, a ação educativa estará condicionada pelo nível de desenvolvimento do aluno, o qual nem sempre vem marcado pelo estudo evolutivo existente, por isso, devem complementar-se com a exploração dos conhecimentos prévios do estudante, ou seja, o que já sabem ou tem construído em seus esquemas cognitivos. Desse modo, unindo a soma de sua competência cognitiva e de seus conhecimentos prévios marcará o nível de desenvolvimento do aluno. 
Figura 2 - Alves tateando $\circ$ material elaborado para $\circ$ estudo de coordenadas sobre uma reta numérica

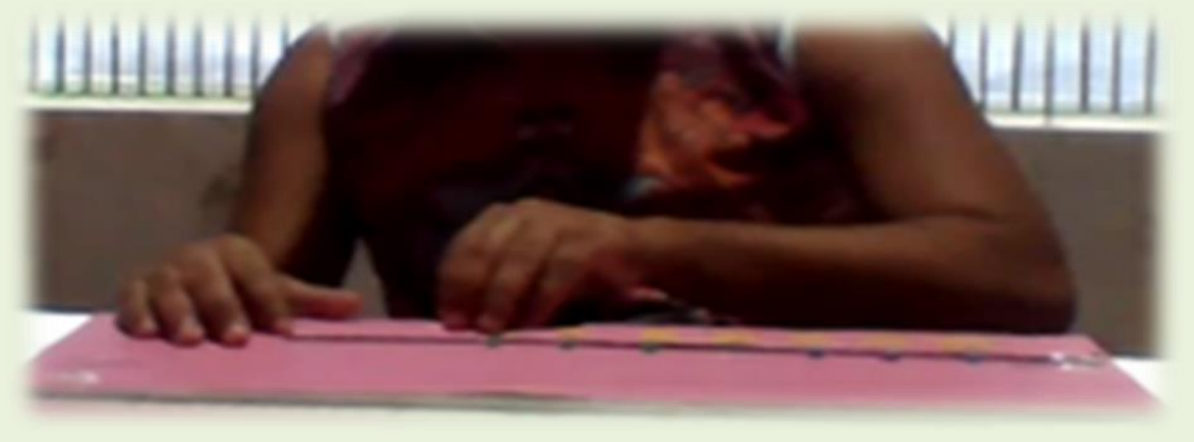

Fonte: Autor.

Para a atividade desenvolvida no El e E2, mostrada na figura 2, foram solicitados ao aluno que tateasse o fio preto representado no plano e, que respondesse o que aquele fio (fio preto) o fazia lembrar? Segundo Vygotsky (1998) o lembrar para o adolescente significa pensar, buscando em sua memória reações lógicas que o permitissem descobrir o elemento que a tarefa exigia que fosse achado, e assim, após algum tempo, Alves conseguiu responder. Este disse que lembrava uma reta (o fio preto). Por meio desta comparação, apresentamos a Alves a reta numérica. Para Mandarino (2010):

A representação dos números em uma reta é um recurso extremamente valioso em Matemática. Pode ser utilizado pelo aluno em todos os níveis de ensino e crescer em importância à medida que este avança (MANDARINO, 2010, p.131).

Desse modo, confirmamos as palavras de Vygotsky (1998), pois o lembrar para Alves o fez pensar, buscar em sua memória a resposta para o questionamento que o fora feito; sendo que o aluno era vidente até aos 10 anos de idade. Após, a resposta de Alves pedimos que ele tateasse o plano de modo geral para identificar cada marcação apresentada no plano, que ainda estava sem a numeração em Braille.

Desse modo, ao final, Alves perguntou o que seria aquele ponto no centro do eixo (fio preto) na figura 2? Para responder à sua pergunta, demos continuidade ao assunto, fazendo o estudante lembrar o que seria o 
conjunto dos números inteiros, quais os números que representam este conjunto e os seus sentidos na reta?

Assim, antes de partir para a escrita Braille dialogamos sobre o conjunto dos números inteiros.

Diante do pensamento Eves (2011), tanto os números naturais, racionais, reais quanto os números inteiros podem ser colocados em uma sequência e representados em uma reta numérica.

Em seguida, partimos para a escrita do código Braille de Matemática, onde escrevemos os números que representam o conjunto dos números inteiros, alocando de forma ordenada a sequência numérica. A partir da escrita, Alves percebeu o significado do ponto no centro da reta numérica, notamos quando Alves afirmava que aquele ponto seria o ponto de partida tanto para os números inteiros positivos quanto para os números inteiros negativos, que independente do sentido a sequência começaria no zero, mas não teria fim. Nesse sentido, corroboramos com Roque (2012), segundo a autora:

Esse 0 não é propriamente um "nada" nem o número negativo é um "menos que nada"; o 0 é o referencial que permite a escolha (decisão) de uma orientação que tornará um número positivo ou negativo (ROQUE, 2012, p. 357).

Nesta etapa, o aluno não apresentou dificuldade em reconhecer o conjunto dos números Inteiros, nem de falar por quais números era representado e dos seus sentidos quanto aos números serem positivos ou negativos.

\section{Encontro (E3 a E4)}

Nessa etapa, tratamos sobre "Coordenadas cartesianas", mas antes disso, dialogamos com o aluno um pouco sobre o contexto histórico da Geometria Analítica. Abordamos que em 1637, Renée Descartes, um matemático e filósofo francês publicou um livro denominado de O Discurso sobre o Método, em que foram estabelecidas as bases filosóficas de seu método para o estudo das ciências, o chamado método cartesiano. No 
apêndice, Descartes ilustra o seu método apresentando a "Géométrie", que foi o passo inicial no estabelecimento de relações mais próximas entre a Álgebra e a Geometria.

Possibilitando a este compreender que a Geometria Analítica, trata, desde a sua origem, das relações entre as equações algébricas e os objetos geométricos, buscando a simplificação técnica dos problemas geométricos e a interpretação geométrica dos resultados obtidos nos cálculos algébricos. E para o estudo desse encontro construímos um plano cartesiano para o estudo das noções básicas em Geometria Analítica.

Nesta perspectiva, foi apresentado ao aluno um plano cartesiano, elaborado com papel cartão, fio, tachinha e fitas adesivas coloridas, sendo que a fita azul era áspera, quanto à fita verde era lisa. Para fazer as notações no plano, elaboramos (pesquisador e aluno) as notações em Braille, referente aos quadrantes, aos eixos e aos números inteiros positivos e negativos. Para isso, foram entregues ao aluno os seguintes recursos: papel $40 \mathrm{~kg}$ em formato A4, punção, prancha e régua adaptada.

Figura 3 - Escrita de códigos matemáticos

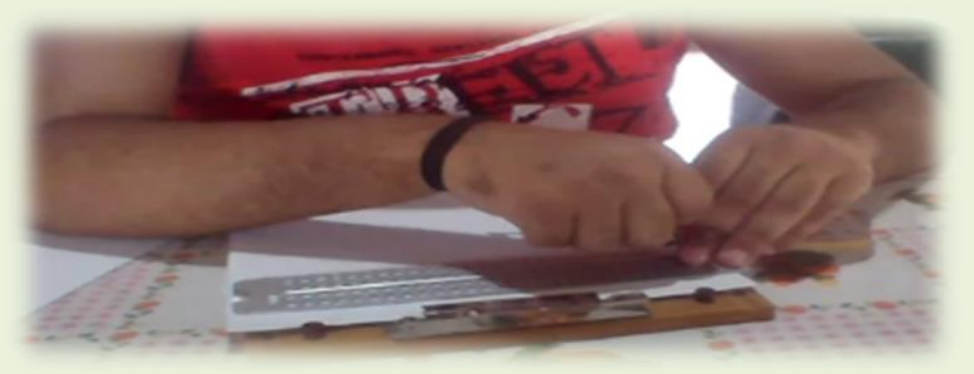

Fonte: Autor.

Para a atividade realizada nos encontros (E3 e E4), mostradas nas figuras 3 e 4 , iniciamos a construção do sistema coordenado cartesiano, para isso, realizamos a escrita de todos os números Inteiros em Braille necessários, e junto do plano anterior foi construído mais uma reta numérica, agora na vertical.

Após esse momento, por meio do tato Alves disse que era como se tivesse duas retas numéricas, uma na vertical e outra na horizontal, mas com algo em comum, o ponto de origem, mostrado na figura 4 . O ponto 0 é 
chamado de origem do sistema de coordenadas e as duas retas são os eixos coordenados. Que a cada ponto estabelecido no plano será associado a um par de números reais $(x, y)$, que são as coordenadas em relação ao sistema. No nosso caso, definimos apenas os números inteiros por fazer parte do conjunto dos números reais.

Figura 4 - Alves tateando as coordenadas cartesianas

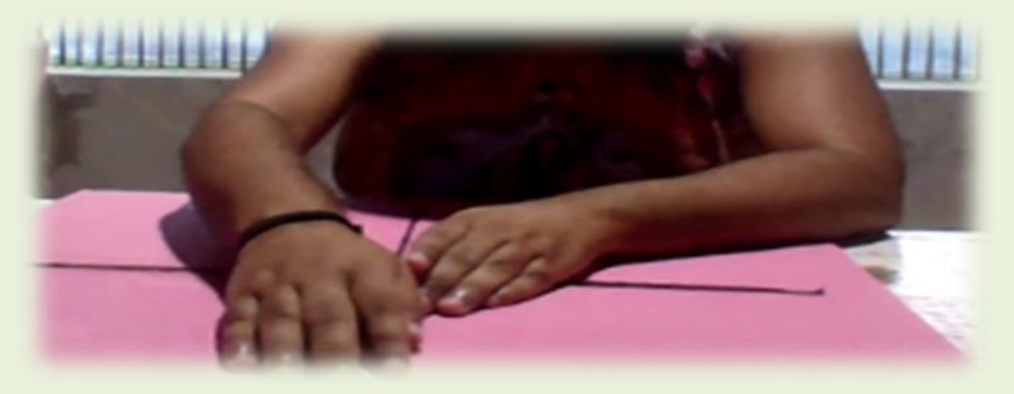

Fonte: Autor.

Nesse momento, notamos que Alves tinha conhecimento dos nomes por ter ouvido o professor falar em sala de aula, mas não por ter tateado a construção do sistema de coordenadas. Segundo Fernandes (2004):

O indivíduo sem acuidade visual dentro dos padrões normais capta e processa informações dos objetos através do sistema háptico (ou tato ativo). Desta forma, o trabalho com estes aprendizes exige a utilização de recursos materiais que possam ser adaptados às suas necessidades específicas (FERNANDES, 2004, p. 37).

Em consonância com o pensamento de Fernandes (2004), identificamos que se o aluno recebesse estímulos adequados para utilizar outros sentidos; como o tato, a fala e a audição; o educando cego estará apto a aprender, desde que se respeite à singularidade do seu desenvolvimento cognitivo. No caso de Alves, suas dificuldades não eram cognitivas, mas sim de ordem material e técnica, fator importante para o seu processo de ensino e aprendizagem.

Desse modo, percebemos que na instituição em que o aluno estudava os professores não faziam uso de materiais manipulativos, recurso este, segundo Alves, necessário na aprendizagem. Para Ferronato (2002, p.107) o 
uso de materiais manipulativos passa a dar significado ao conteúdo erudito e facilita o processo de aprendizagem.

Moraes (2016) em sua pesquisa realizou os efeitos de desbrailização em aulas de matemática para uma aluna cega do ensino fundamental, como estratégia para explorar a percepção tátil, criou-se um transferidor $360^{\circ}$ adaptado, denominado de T360 A, a fim de substancializar o estudo de ângulos, incentivando a escrita e a leitura em Braille.

Notamos como o transferidor $360^{\circ}$ adaptado, foi importante para $\circ$ ensino e aprendizagem da aluna, segundo Moraes (2016) ainda há uma carência de preparação de materiais em Braille para alunos com deficiência visual havendo a necessidade de investigações que apontem caminhos que possam diminuir os obstáculos enfrentados pelos estudantes com deficiência visual.

Corroboramos com Lírio (2006, p. 8) ao inferir que:

Para que o aprendizado de conceitos como forma, tamanho, espaço-temporal, esquema corporal, causalidade e pensamento lógico matemático se processe de forma adequada, precisamos promover a concretização dos mesmos através de materiais pedagógicos que possam ser assimilados pelos outros sentidos.

Nesse ponto inferimos que parte da dificuldade enfrentada por Alves estava relacionado à falta de material adequado. Nessa atividade, Alves também percebeu que por meio do cruzamento dos eixos x (abscissa) e y (ordenadas) o plano havia sido divido em quatro regiões denominadas de quadrantes. Neles, os pontos do primeiro quadrante são pontos cujas coordenadas são ambas positivas; os do terceiro a pontos cujas coordenadas são ambas negativas. No segundo quadrante, temos pontos cuja primeira coordenada é negativa e a segunda é positiva, o contrário ocorrendo para os pontos do quarto quadrante.

Para compreender melhor o significado dos quadrantes, foram necessários representá-los em código Braille de Matemática e analisar os eixos x (abcissa) e y (ordenada) de acordo com os seus quadrantes, como mostrado na figura 5 . 
Nesta etapa, realizamos juntos com Alves a leitura dos eixos $x$ e y no primeiro quadrante, nesse momento, pedimos a Alves para tatear os números atribuídos ao eixo x (abcissa) e se eram positivos ou negativos, em seguida, demos o mesmo comando a Alves para o eixo y (ordenada), e solicitamos que fizesse o seu registro em Braille.

Figura 5 - Quadrantes no plano

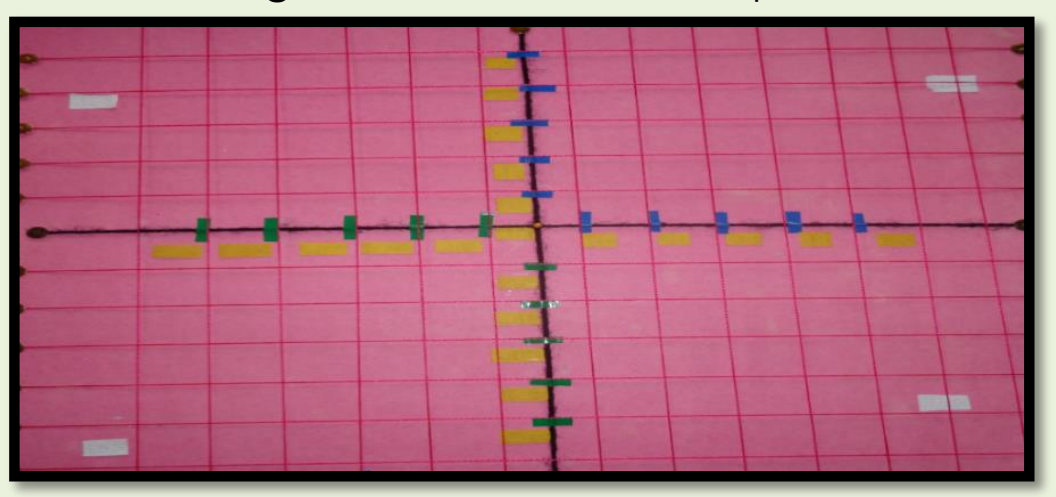

Fonte: Autor.

Essa tarefa chamou bastante à atenção de Alves, segundo ele, foi nesta atividade que havia compreendido o que seria um quadrante e como se fazia a leitura dos eixos $x$ e $y$ de acordo com os quadrantes.

Além disso, Alves mostrou mais interesse devido estar registrando as atividades e praticando mais o código Braille de Matemática, segundo este, não fazia registros na sala de aula porque sabia como era o código de alguns termos da Matemática, mas o professor da turma não sabia utilizar o Braille.

\section{Encontro (E5 a E6)}

Para este momento, reutilizamos o material construído no encontro anterior. O material manipulável fora projetado para ser construído com objetos de baixo custo e que fosse acessível a todos. Mas, antes de dar continuidade, dialogamos com Alves sobre o assunto referente à distância entre dois "pontos", em seguida, fomos para a prática. A pedido do aluno, descrevemos os exemplos em Braille. A distância entre dois pontos (que é também o comprimento do segmento) é dada pelo valor absoluto da 
diferença entre os números reais correspondentes a esses pontos. Mas, na análise referente ao cálculo da distância, o estudante sempre voltava ao material manipulável para tatear e por seguinte responder o resultado.

Figura 6 - Distância entre dois pontos

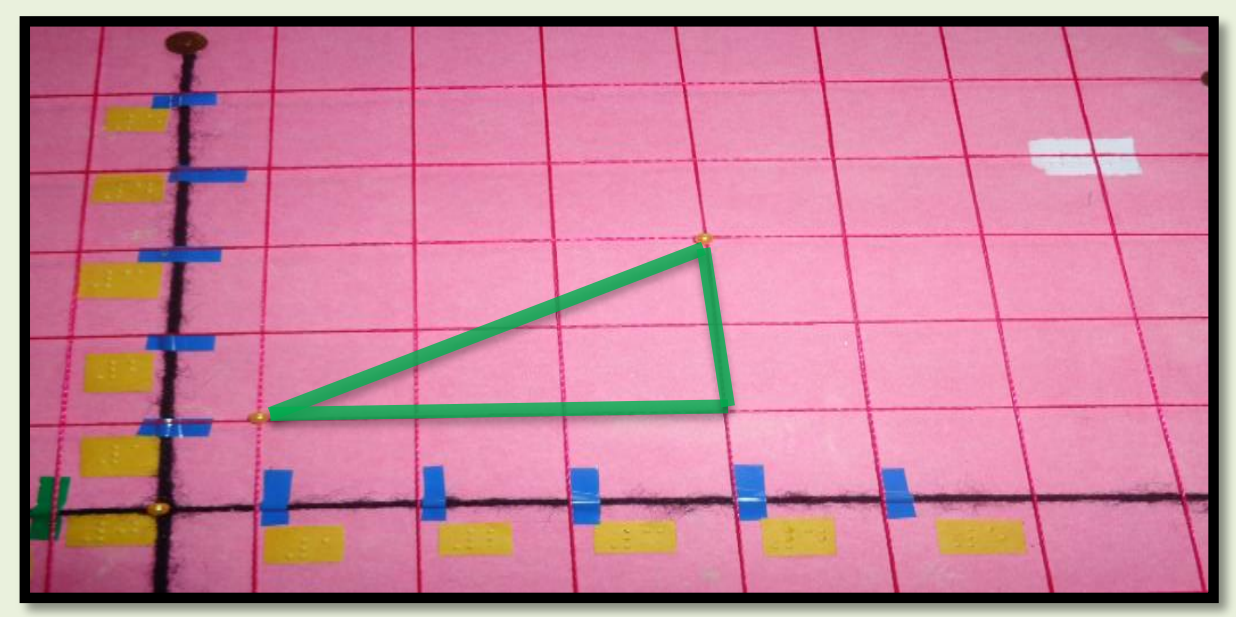

Fonte: Autor.

No decorrer das tarefas, notamos um crescimento significativo de Alves. Nas atividades expostas no E5 e E6, mostrada na figura 6, trabalhamos distância entre dois pontos, para chegarmos até o desenvolvimento do cálculo, primeiro determinamos as coordenadas de dois pontos, dentre alguns exemplos utilizamos os pontos $A(2,1)$ e $B(6,4)$, para isso, traçamos linhas perpendiculares aos eixos $x$ e $y$.

Deste modo, Alves tateava os números correspondentes a cada eixo e fazia a operação no soroban7, ao representar os números em cada eixo, pedimos para Alves tatear os novos pontos que foram formados, em seguida, que ao final do segundo ponto tocasse com o dedo indicador da mão esquerda a linha paralela ao eixo y para baixo e com o indicador da sua mão direita tocasse o primeiro ponto formado deslizando para a direita na linha paralela ao eixo $x$.

Sendo que ambos os movimentos teriam que ser realizados ao mesmo tempo, ao final, deste comando, perguntamos o que havia percebido. Após

\footnotetext{
7 O soroban é um aparelho de cálculo usado há muitos anos no Japão em escolas, Tem manejo simples e torna o ato de calcular algo concreto, permitindo mais rapidez e agilidade de raciocínio.
} 
algum tempo, respondeu que elas se cruzavam, a partir daí, solicitamos a ele que unisse o segmento $\overline{A B}$ até o ponto de encontro das linhas traçadas com as mãos.

Nesse ponto, perguntamos se algo era formado, em princípio, Alves não percebeu nada. Então, decidimos fazer com um pequeno pedaço de barbante o mesmo trajeto que Alves fez com as mãos. Com essa construção, Alves disse que formava uma figura geométrica, a qual conhecia por triângulo retângulo, percebendo isso pelo encontro das linhas traçadas aos eixos que formavam um ângulo reto. Assim, perguntamos do que ele lembrava quando falávamos em triângulo retângulo.

Alves disse que se lembrava do teorema de Pitágoras e, até ditou a fórmula que havia memorizado.

Assim, o tato permite analisar o objeto de forma parcelada e gradual, ao contrário da visão que é sintética e global (FERNANDES, 2004, p.41). Assim, as informações parciais fornecidas pelo tato têm um caráter sequencial que devem ser integradas, exigindo uma carga maior de memória (GIL, 2000, p.25). Ao explorar um objeto, as mãos do não vidente movem-se de forma intencional, captando particularidades da forma a fim de obter a imagem do objeto (OCHAITA; ROSA, 1995, p.185).

Dessa forma, a construção do material manipulável por Alves ocorreu aos poucos, pois é tateando por parte que este chega a formar a imagem do todo, ao estabelecer sentido em tudo o que foi explorado, Alves percebeu que calcularíamos a distância do ponto $A$ até o ponto $B$, utilizando o teorema Pitágoras, com o auxílio do material manipulativo e do soroban. A partir do exemplo adotado, referente aos pontos $A$ e B, foi realizado o cálculo e chegamos a um resultado.

No final da atividade, Alves perguntou se iriam utilizar os dois resultados ou apenas um, que seriam +5 ou -5 . Para responder a esse questionamento, utilizamos uma fita métrica e medimos juntos os espelhos de uma mesa. Naquele momento, obtivemos como resultado $2 m$, em seguida, fizemos a seguinte indagação a Alves: $E$ se fosse $-2 m$ ? Alves responde de imediato e 
diz: - 2m não pode ser, pois dá a ideia de que estou reduzindo o espelho da mesa em $2 m$.

Assim sendo, notamos que Alves pelo seu conhecimento conseguiu compreender que o comprimento não é negativo, e ao tratar de comprimento nos referimos à distância, assunto deste encontro, desse modo, Alves compreendeu que iria utilizar o resultado positivo.

Segundo Fernandes (2004) um dos principais fatores que envolvem uma situação de aprendizagem é a intervenção do outro, ao estabelecer situações interativas com os sujeitos envolvidos numa situação de aprendizagem por meio dos sistemas de mediação, favorecendo o planejamento e a regulação das atividades de aprendizagem.

\section{Conclusão}

Não temos a intenção de efetuar julgamentos ou acepções, mas questionamentos no sentido de contribuir em futuros trabalhos sobre 0 assunto e provocarmos algumas ponderações do que sinalizam e apontam os dados produzidos no ambiente escolar desenvolvido na referida pesquisa.

A escola é um espaço onde existem diversas personalidades, que se situam não apenas no espaço da escola, mas também fora dela, em contextos que envolvem a comunidade escolar, a família e outros grupos sociais.

Por isso a escola é entendida segundo Galvão, Santos e Araújo (2009, p.255) como um espaço fundamental para $\circ$ desenvolvimento $e$ aprendizagem do ser humano, mas ao mesmo tempo as vivências escolares estão presentes nas nossas histórias de vida.

Portanto, vemos que é na interação com a comunidade escolar que o aluno dialeticamente constrói a si próprio. Na troca com o outro, o sujeito se constitui.

Para Vygotsky (1998, p. 37):

A maior mudança na capacidade das crianças para usar a linguagem como um instrumento para a solução de problemas 
acontece um pouco mais tarde no seu desenvolvimento, no momento em que a fala socializada (que foi previamente utilizada para dirigir-se a um adulto) é internalizada. Ao invés de apelar para o adulto, as crianças passam a apelar a si mesmas; a linguagem passa, assim, a adquirir uma "função intrapessoal" além do seu "uso interpessoal". No momento em que as crianças desenvolvem um método de comportamento para guiarem a si mesmas, o qual tinha sido usado previamente em relação a outra pessoa, e quando elas organizam sua própria atividade de acordo com uma forma social de comportamento, conseguem, com sucesso, impor a si mesmas uma atitude social (grifos do autor).

Para Vygotsky (1998), a linguagem faz parte dessa interação que funciona como elemento mediador que permitem a comunicação entre as pessoas e $O$ estabelecimento de significados compartilhados por determinada cultura. A linguagem se manifesta, portanto, como uma ferramenta importante para que o homem se constitua enquanto sujeito.

Percebemos que, a utilização do material manipulativo ressalta vários aspectos pedagógicos positivos, tais como: o interesse, a atenção, o diálogo, a participação efetiva, a motivação, a interação, a integração e a aprendizagem articulada da geometria e da álgebra. Na construção dos materiais manipuláveis, utilizamos materiais de baixo custo e, abordando assim, o ensino da Geometria Analítica.

O material manipulativo como mediador no processo de ensino e aprendizagem de Geometria Analítica, evidenciou a internalização descrita por Vygotsky, como processo de construção das funções superiores e esse mecanismo são chamados por ele o mecanismo de internalização ou também Interiorização, nesse processo, a utilização de marcas externas vai se transformar em processos internos de mediação no uso dos signos.

Ao comparar os movimentos das mãos de Alves no decorrer das atividades propostas com a ferramenta, são nítidas as mudanças no modo que ele explorou este espaço e como o plano cartesiano começou a compor parte de seus recursos cognitivos em relação às atividades. Estas evidências nos levaram a concluir que o material manipulativo realmente serviu como papel mediador na compreensão das noções básicas de Geometria Analítica. Com certeza esta foi sua primeira experiência em ler e construir um plano cartesiano. 
Desse modo, pensando na direção dos alunos com deficiência visual nas aulas de matemática, notamos ser indispensável o uso de material manipulável, pois possibilitam ao aluno "ver" o que está sendo falado e, como representação da sua compreensão este pode mostrar por meio do material manipulável o que internalizou.

Nesse sentido, durante as atividades que se seguiram, pudemos observar que Alves possuía vários conhecimentos em relação à Geometria Analítica, porém, por meio do material conseguia de maneira clara identificar onde estavam suas dúvidas de forma independente. Constatando, que a cegueira não apresenta um impedimento para que o estudante tenha acesso ao conhecimento matemático, em especial a Geometria Analítica. Mas, que estratégias devem ser criadas e que os recursos sejam utilizados de forma a permitir que o estudante cego participe ativamente do processo de ensino-aprendizagem de Matemática.

Verificamos, por meio do relato do aluno, ao longo das atividades, principalmente, grandes dificuldades quando não havia a utilização, por parte de seus professores anteriores, de um material manipulável para the auxiliar nas aulas de matemática. O aluno com deficiência visual sem um material adequado, segundo ele, somente imagina como deve ser a situação exposta pelo professor e essa "imaginação" muitas vezes não é a maneira correta.

De acordo com Sales (2013), ainda há muitas dificuldades de se efetivar a inclusão na questão do ensino da matemática, pois "encontramos nas salas de aula, professores que se julgam não preparados e, consequentemente, com dificuldades para desenvolver métodos e adaptações necessárias aos novos alunos" (SALES, 2013, p. 39).

Nesse estudo, buscamos algumas formas que um professor pode fazer para melhorar o processo de ensino e aprendizagem ao aluno com cegueira, pois as atividades podem ser desenvolvidas tanto com deficientes visuais (cegos e baixa visão) quanto com deficientes auditivos, e assim, caminhando à enorme tarefa que todos os educadores têm. Realizamos atividades individuais e confeccionamos uma ferramenta que pudesse 
proporcionar igual condição ao aluno cego com relação aos outros alunos sobre o estudo de noções básicas de Geometria Analítica.

Apesar das leis destinadas a normatizar o processo de inclusão de alunos com necessidades educacionais especiais, muitas pessoas ligadas a Educação afirmam não se sentirem preparadas para enfrentar tal desafio (FERNANDES; HEALY, 2007). Na verdade, nota-se que a partir das políticas de inclusão há a necessidade de preparar a comunidade educacional para receber estes alunos. Nesse sentido, a Declaração de Salamanca (1994) diz que:

O princípio fundamental das escolas inclusivas consiste em que todos os alunos devam aprender juntos, sempre que possível, independentemente das dificuldades e das diferenças que apresentem. As escolas inclusivas devem reconhecer e satisfazer às necessidades diversas dos seus alunos, adaptando aos vários estilos e ritmos de aprendizagem, de modo a garantir um bom nível de educação para todos, através de currículos adequados, de uma boa organização escolar, de estratégias pedagógicas, de utilização de recursos e de uma cooperação com as respectivas comunidades. É preciso, portanto, um conjunto de apoios de serviços para satisfazer o conjunto de necessidades especiais dentro da escola (BRASIL, 1994, p.5).

Entendemos que o estudante com deficiência visual precisa de condições para atender às suas necessidades educativas não somente para aprender, mas também para socializar. Pois se faz necessário compreender que o significado de inclusão abrange o acesso, a permanência e progresso na sua vida acadêmica e social.

A Educação Matemática pode ser acessivel a todos os alunos desde que sejam dados aos estudantes os recursos didáticos necessários para a construção do conhecimento. Como corrobora Silva e Pinto (2010, p.47):

Nossas escolas não estão adaptadas para receber crianças cegas ou com outra deficiência, pois não possuem infraestrutura física e nem material adequado para que essas crianças desenvolvam suas habilidades da melhor forma possível, provocando falhas de aprendizagem e desenvolvimento. Como consequência, os recursos didáticos são pouco explorados, e deixam muitas vezes de fora esses objetos que poderiam contribuir para uma melhor aprendizagem, tanto dos deficientes visuais quanto dos videntes, executando realmente ações que contribuam de forma significativa para que a inclusão ocorra. 
Nesta perspectiva, é necessário que os alunos recebam as condições necessárias de ensino, independente de terem ou não necessidades educativas especiais (NEE) sem deixar de pensar na linguagem e na metodologia a ser utilizada, pois apenas o domínio do conteúdo matemático não parece ser suficiente. Além disso, o professor necessita conhecer a linguagem e/ou código de escrita no caso do aluno cego, e, além disso, desenvolver metodologias para ministrar suas aulas.

Esta pesquisa ampliou nossa compreensão em relação à temática e consolidou a concepção de que o tempo de aprendizagem é diferente para cada aluno, e isso pode favorecer uma aprendizagem coletiva dos alunos.

Desse modo, consideramos que os pontos apresentados de algum modo contribuíram significativamente para a área da educação matemática inclusiva, pois na medida em que ocasionam importantes reflexões sobre o processo de formação das funções psicológicas superiores 8 , também, promovem questionamentos, indicam caminhos e estimula a criação de alternativas no campo didático-pedagógico.

Portanto, nesta pesquisa foram descritas diversas situações, envolvendo aspectos significativos para pesquisas em Educação Matemática Inclusiva, sugerimos um novo olhar ao ensino de Matemática para estudantes cegos, com a utilização de materiais manipulativos e outras tecnologias, buscando integrar aspectos cognitivos e sociais em atividades que promovam a inclusão destes estudantes.

\section{Referências}

AUSUBEL, D. P. A aprendizagem significativa: a teoria de David Ausubel. São Paulo: Moraes, 1982.

CAPELLINI, V. L. M. F.; RODRIGUES, O. M.P. R. Concepções de professores acerca dos fatores que dificultam o processo da educação inclusiva.

Educação, Porto Alegre, v. 32, n. 3, p. 355-364, set./dez. 2009. Disponível em:

8 Capacidade própria do ser humano de lembrar, imaginar, planejar. Diferencia-se de mecanismos mais elementares como ações reflexas, reações automatizadas e associações simples entre eventos (OLIVEIRA, 2002, p.26). 
http://revistaseletronicas.pucrs.br/ojs/index.php/faced/article/viewFile/5782/ 4203. Acesso em: 30 jan. 2016.

CERQUEIRA, J.B.; FERREIRA, E.M.B. Recursos didáticos na Educação especial. Revista Benjamin Constant, Rio de Janeiro, n.15, p.24 - 28, 2000.

EVES, H. Introdução à história da matemática. Tradução: Hygino H. Domingues. $5^{a}$ ed. Campinas: Editora da Unicamp, 2011.

FERNANDES, S. H. A. A. Uma análise vygotskiana da apropriação do conceito de simetria por aprendizes sem acuidade visual. 2004. 300f. Dissertação (Mestrado em Educação Matemática), Pontifícia Universidade Católica de São Paulo, São Paulo/SP, 2004.

FERNANDES, S. H. A. A.; HEALY, L. Ensaios sobre a inclusão na Educação Matemática. Revista Iberoamericana de Educacão Matemática, n.10, p. 5976, 2007. ISSN 1815-0640.

FERRONATO, R. A construção de instrumento de inclusão no ensino da Matemática. 2002. 139 f. Dissertação (Mestrado em Engenharia de Produção) - Universidade Federal de Santa Catarina, Florianópolis/SC, 2002.

GALVÃO, N.C.S.S.; SANTOS, M. J.; ARAÚJO, S.C. Deficiência visual e surdocegueira. Educação inclusiva, deficiência e contexto social: questões contemporâneas, Salvador: EDUFBA, 2009. Disponível em: http://books.scielo.org. Acesso em: 20 mar. 2016.

GIL, M. Deficiência visual. Cadernos da TV escola. n.1, p.22-32, Brasília: MEC. Secretaria de Educação a Distância, 2000. ISSN 1518-4692.

GLAT \& NOGUEIRA, M. L. de L. Políticas educacionais e a formação de professores para a educação inclusiva no Brasil. Comunicações, São Paulo, n.1, v.10, p.134-142, 2003. DOI: http://dx.doi.org/10.15600/2238-

121X/comunicacoes.v10n1p134-142. Disponível em: https://www.metodista.br/revistas/revistasunimep/index.php/comunicacoes/article/view/1647. Acesso em: 21 maio 2016.

HILDEBRANDT, H. T. Contando a história do IBC através de alguns de seus regimentos, Rio de Janeiro, set. 2004. Disponível em: http://acervo.ibc.gov.br/. Acesso em: 16 abr. 2016.

HUSSERL, E. A Ideia da Fenomenologia. Lisboa: Edições 70, 1986.

LIRIO, S. B. A Tecnologia Informática como Auxílio no Ensino de Geometria para Deficientes Visuais. 2006. 129f. Dissertação (Mestrado em Educação Matemática) - Universidade Estadual Paulista, Rio Claro/ SP, 2006. 
MANDARINO, M.C.F. Números e operações. In: PITOMBEIRA, J.B; CARVALHO, F. (Org.). Coleção explorando o ensino-Matemática, v.17, Brasília, SEB/MEC, 2010. p. 97-134.

MORAES, M. E. L. de. A leitura tátil e os efeitos da desbrailização em aulas de matemática. 2016.319f. Dissertação (Mestrado em Educação em Ciências e Matemáticas) - Universidade Federal do Pará, Belém, 2016.

OCHAITA, E.; ROSA, A. Percepção, ação e conhecimento nas crianças cegas. In: COLL, C; PALACIOS, J.; MARCHESI, A. (Org.). Desenvolvimento Psicológico e Educação: necessidades educativas especiais e aprendizagem escolar. Tradução Marcos A. G. Domingues. Porto Alegre: Artes Médicas, 1995. p.183-197.

REYS, R. Considerations for teaching using manipulative materials. The Aritmetic Teachers. v. 18, n.8, dec.1971, p. 551-558. Reston: NCTM.

ROQUE, T. História da Matemática: uma visão crítica, desfazendo mitos e lendas. Rio de Janeiro: Zahar, 2012.

SALES, E. R. de. Refletir no silêncio: um estudo das aprendizagens na resolução de problemas aditivos com alunos surdos e pesquisadores ouvintes. 2008. 162f. Dissertação (mestrado em Educação em Ciências e Matemáticas) - Universidade Federal do Pará, Belém/PA, 2008.

SILVA, L. M. S. da. Do improviso às possibilidades de ensino: estudo de caso de uma professora de matemática no contexto da inclusão de estudantes cegos. 2015. 200f. Tese (Doutorado em Educação Matemática) Universidade Estadual Paulista "Júlio de Mesquita Filho", Rio Claro/ SP, 2015.

SILVA, M.C.R.F.; PINTO, T.C.L. Inclusão social: o design como parte integrante no ensino da arte. Revista Educação, Arte e Inclusão, n.1, p. 1-10, Florianópolis, v. 02, 2009. Disponível em: http://www.revistas.udesc.br/index.php/arteinclusao/article/view/2005/1560. Acesso em: 02 março 2016. ISSN 1984-3178.

VIEIRA, S. S. \& SILVA, F. H. S. Flexibilizando a Geometria na Educação Inclusiva dos Deficientes Visuais: uma proposta de atividades. In: IX Encontro Nacional de Educação Matemática, 2007.

VYGOTSKY, L. S. A formação social da mente: o desenvolvimento dos processos psicológicos superiores. São Paulo: Martins Fontes, 1998.

VYGOTSKY, L. S. Obras Escogidas V: fundamentos de defectologia. Madrid: Visor, 1997. 
YIN, R. K. Estudo de Caso: Planejamento e Métodos. Tradução: Daniel Grassi. 3. ed. Porto Alegre: Bookman, 2005.

Recebido em: 12 de abril de 2020

Aprovado em: 01 de julho de 2020

Publicado em: 02 de setembro de 2020

(c) $\underset{\mathrm{BY}}{(\mathrm{i})}$ (9) 